\title{
Teoria Institucional e Finanças: uma Revisão Sistemática da Literatura
}

\section{Institutional Theory and Finance: a Systematic Literature Review}

\author{
Anderson Dias Brito \\ Universidade Federal da Paraíba - UFPB - Brasil \\ andersonbrito.adm@gmail.com \\ ORCID: https://orcid.org/0000-0003-0783-3884 \\ Allisson Silva dos Santos \\ Universidade Federal da Paraíba - UFPB - Brasil \\ allissonst@hotmail.com \\ ORCID: https://orcid.org/0000-0001-5121-9553 \\ Jucimar Casimiro de Andrade \\ Universidade Federal Rural de Pernambuco - UFRPE- Brasil \\ jucimarcandrade@gmail.com \\ ORCID: https://orcid.org/0000-0001-5539-4498
}

\author{
Recebido: 27 Março 2021 \\ Revisado: 30 Junho 2021 \\ Aceito: 24 Agosto 2021
}

\begin{abstract}
Resumo
Objetivo: Esta revisão sistemática qualitativa teve por objetivo identificar os avanços dos estudos em finanças que estão utilizando a Teoria Institucional como plataforma teórica. Metodologia: Foram examinados 65 artigos, sendo 12 nacionais e 53 internacionais. Destes, foram selecionados 4 artigos de periódicos nacionais e 28 de periódicos internacionais para a realização da revisão sistemática da literatura, sendo excluídos 33 artigos por não atenderem os critérios da pesquisa de: estar relacionado ao campo das finanças e utilizar da Teoria Institucional como base para as discussões. Resultados: Os resultados demonstram o entendimento da Teoria Institucional como uma lente teórica que pode auxiliar na compreensão de fenômenos na área de finanças, como, por exemplo, governança corporativa, mensuração e divulgação do desempenho, fusões e aquisições, finanças culturais, riscos, decisões de investimento e financiamento e implicações do gerenciamento de resultados. Contribuições: Há contribuições para reforçar a Teoria Institucional, ao mostrar quanto as características institucionais interagem de maneira complementar para o desenvolvimento dos mercados financeiros ao adotarem práticas que sejam legitimadas pelos principais stakeholders. Nas contribuições para as finanças, foi possível observar um passo adiante à reestruturação do campo, ao incorporar pressões sociais e internacionais em pesquisas. Para os formuladores de políticas, reguladores e gestores, a legislação poderá ser adotada de maneira a melhorar os processos gerenciais, ou ser adotada por questões de legitimidade perante os stakeholders para garantir a sobrevivência por mais tempo. Por outro lado, a dinâmica do ambiente poderá não ser aceita pelas organizações, e essas migrarem para outros ambientes que melhor lhes convém.
\end{abstract}

Palavras-chave: Teoria Institucional. Finanças empresariais. Legitimidade. Características institucionais.

\begin{abstract}
Objective: This qualitative systematic review aimed to identify advances in finance studies that are using Institutional Theory as a theoretical platform. Methodology: 65 articles were examined, 12 national and 53 international. Thus, 4 articles from national journals and 28 from international journals were selected for the systematic review of the literature, 33 articles were excluded for not meeting the research criteria because: they are not related to the field of finance and use Institutional Theory as a basis for discussions. Results: The results demonstrate the understanding of Institutional Theory as a theoretical line that can help to understand phenomena in the area of finance, such as corporate governance, performance measurement and disclosure, mergers and acquisitions, cultural finance, risks, decisions of investment and financing and implications of earnings management. Contributions: There are contributions to reinforce the Institutional Theory, by showing how institutional characteristics interact in a complementary way for the development of financial markets by adopting practices that are legitimized by the main stakeholders. In relation to the contribution to the field of finance, it was possible to observe a step forward in the restructuring of the field, by
\end{abstract}


incorporating social and international pressures into research. For policy makers, regulators and managers, legislation may be adopted in order to improve management processes, or be adopted for reasons of legitimacy with stakeholders to ensure longer survival. On the other hand, the dynamics of the environment may not be accepted by organizations, and these may migrate to environments that are better for them.

Keywords: Institutional Theory. Corporate finance. Legitimacy. Institutional features.

\section{Introdução}

A década de 50 foi um período de revolução no campo das finanças em que muitos conceitos foram reformulados, e assim surgiu a Moderna Teoria Financeira. Essa teoria trouxe resultados no desenvolvimento de inúmeras ferramentas usadas nos processos de tomada de decisões de investimento (Chhatwani, 2019), financiamento (Iquiapazza, Amaral \& Bressan, 2009) e dividendos (Simkowitz, 1972). Enquanto o conhecimento em finanças no modelo tradicional era baseado na experiência, os modernos teóricos exploram mais o homo economicus da Teoria Neoclássica, tendo maior apego à normatização, matematização e universalização.

Com as características da Teoria Moderna em finanças de normatizar e universalizar, surge espaço para diálogo com a Teoria Institucional. Essa Teoria Institucional possibilita diversas abordagens em estudos organizacionais (Burns \& Scapens, 2000) e, sob ótica da Nova Sociologia Institucional, se apresenta como uma das que se preocupa em estudar as diferenças, a homogeneidade de formas e as práticas observadas em diferentes organizações (Almeida \& Callado, 2017).

De maneira geral, a Teoria Institucional concentra-se na estrutura e procedimentos organizacionais (normas, regulamentos e pressões) que são moldados por fatores externos e afetam o comportamento organizacional em busca de legitimidade (Moll, Burns \& Major, 2006). A Teoria Institucional pode ser aplicada para explicar esse processo de legitimação e na compreensão dos padrões e processos de mudança organizacional (Soeiro \& Wanderley, 2019). De acordo com Bender (2004), as explicações dadas para isso incluem isomorfismo coercitivo (a necessidade de atender aos requisitos dos reguladores) e isomorfismo mimético (o desejo de ser como outras empresas que são percebidas como modelos a serem seguidos).

A Teoria Institucional tem se mostrado como ferramenta útil para oferecer suporte às discussões no âmbito das finanças, mais precisamente na Governança Corporativa (Ntim \& Soobaroyen, 2013; Chakrabarty \& Bass, 2014; Yamahaki \& Frynas, 2016), na estrutura de capital (Driffield, Mickiewicz \& Temouri, 2014), nos investimentos (Derouiche, Muessig \& Weber, 2020; Kwabi, Boateng, \& Adegbite, 2018), nas fusões e aquisições (Attah-Boakye et al., 2020; Du, Boateng \& Newton, 2015), nas finanças culturais (Goodell, 2019), nas implicações do gerenciamento de resultados (Eng et al., 2019) e na análise e mensuração de desempenho (Russo et al., 2012; Almeida \& Callado, 2017).

Em um campo amplo que são as finanças, a Teoria Institucional oferece suporte na fundamentação das discussões para ajudar a explicar a realidade do mercado e as ações das organizações que estão nele inseridas. Apesar do avanço na literatura em finanças que usa Teoria Institucional como fundamentação teórica, não foram encontrados estudos tanto a nível nacional, quanto internacional que reunissem e analisassem de maneira sistemática, como essa teoria está sendo utilizada no campo das finanças.

Ante os argumentos expostos, o presente estudo busca responder a seguinte indagação: quais são os avanços e tendências das investigações em Finanças que se utilizam da Teoria Institucional? Dessa forma, o presente estudo apresenta uma revisão sistemática qualitativa da literatura, que reúne o conhecimento no campo das finanças com o uso da Teoria Institucional, além de reconhecer aspectos relevantes, tendências e cenários das investigações.

\section{Teoria Institucional}

A Teoria Institucional consegue explicar, de maneira robusta, a ação individual e organizacional (Dacin, Goodstein, \& Scott, 2002). Essa teoria considera que o comportamento social é moldado por padrões desenvolvidos, por meio de interações humanas, e incorporados em normas e regulamentos organizacionais, para alcançar legitimidade (Barley \& Tolbert, 1997; Moll, Burns \& Major, 2006). As explicações dadas para a obtenção de legitimidade incluem dois tipos de isomorfismo: coercitivo (a necessidade de atender aos requisitos dos reguladores) e mimético (o desejo de ser como outras empresas que são percebidas como referências positivas) (Bender, 2004).

Os elementos formais da estrutura organizacional, como políticas e procedimentos, surgem da expectativa social generalizada e de mitos e apresentam manifestações de regras institucionais. Ambientes que institucionalizam um número expressivo de mitos racionais, geram uma organização mais formal. Além disso, as organizações que se apropriam de mitos institucionalizados são mais legítimas e sobrevivem mais no mercado (Meyer \& Rowan 1977). 
Conforme a Teoria Institucional, as instituições representam restrições de opções que as pessoas são coagidas a exercer, seja de forma coletiva ou individual. Essas restrições definem limites à racionalidade humana, comprimindo alternativas e oportunidades, e intensificando a ocorrência de comportamentos pré-definidos (Barley \& Tolbet, 1997). Não obstante, a institucionalização pode ser entendida como um processo pelo qual os indivíduos habitam no que é definido socialmente como real. A garantia de um maior grau de institucionalização pode proporcionar uma maior uniformidade dos entendimentos culturais e uma maior resistência à mudança por influência pessoal (Zucker, 1977).

Ao considerar o ciclo de vida corporativo, as instituições reagem de maneira diferente durante seus estágios. No estágio inicial, as áreas organizacionais apresentam diversidade em forma e abordagem de atuação. Em contrapartida, a partir do momento que as áreas organizacionais se solidificam, há um impulso para a homogeneização, se tornando áreas mais semelhantes umas às outras. Parte dos arranjos estruturais onipresentes são mais percebidos pelos processos miméticos do que por evidências de que os modelos adotados maximizam a eficiência organizacional. Dessa forma, algumas alternativas estruturais são vistas como menos desejáveis ou apropriadas, e a prática do isomorfismo institucional se constitui como justificável para as organizações se tornarem homogêneas (Dimaggio \& Powell, 1983; Dacin, Goodstein, \& Scott, 2002).

Três correntes da Teoria Institucional são discutidas em estudos organizacionais: a) Nova Sociologia Institucional (NIS - New Institutional Sociology); b) Nova Economia Institucional (NIE - New Institutional Economics); e c) Velha Economia Institucional (OIE - Old Institutional Economics). Essas correntes surgem de divergentes raízes filosóficas, mas possuem comum interesse em discutir a natureza da instituição e da mudança institucional (Guerreiro et al., 2005).

A corrente NIS trata as instituições como uma extensa cadeia de relacionamentos e complexos culturais. $O$ contexto institucional influencia crenças, tradições e normas das empresas, como, também, o relacionamento entre elas. Para receber legitimidade e apoio, indivíduos e organizações precisam se conformar com as regras, práticas e crenças criadas pelo ambiente institucional (Scapens, 2006). As premissas instauradas pela abordagem NIS consideram que o conformismo das organizações perante as normas sociais é necessário para garantir a sobrevivência e o nível elevado de eficiência produtiva (Covaleski; Dirsmith \& Samuel, 1996).

A corrente NIE utiliza de arranjos contratuais institucionais e da pressão competitiva dos mercados como instrumentos para justificar a existência de organizações capitalistas e dos custos de transação. Essa corrente traduz o ambiente institucional como um conjunto de regras formais e políticas, elaboradas por autoridades governamentais, que estabelecem as bases para troca, produção e distribuição em um contexto de evolução empresarial. Os custos de mensurar as dimensões de serviços e produtos, os desempenhos dos indivíduos e os custos de definir acordos são referenciados como os custos de transação (Pereira \& Lopes, 2018).

No que diz respeito à corrente $O I E$, a instituição se torna o foco de análise e ocupa o espaço principal de estudos organizacionais, antes ocupado pelo interesse no comportamento racional e maximizador de utilidade. As premissas teóricas por trás da OIE correspondem ao caráter coletivo, de dar significado ao comportamento organizacional e de orientar ações. Além disso, as organizações desenvolvidas se tornam destaque pela atuação rotineira da atividade humana. As rotinas são hábitos formais institucionalizados que promovem o comportamento baseado em regras fundamentais para fomentar a coerência nas atividades exercidas pelas equipes de trabalho, o que garante qualidade na execução dos processos operacionais (Guerreiro et al., 2005).

Numa tentativa de conceituar a Teoria Institucional com base na evolução de seus significados, o histórico de ações e acontecimentos são capazes de gerar normas e regras que moldam a realidade atual e os hábitos futuros. Como denotado, a formação da Teoria Institucional possui diversas vertentes que podem explicar a variedade de respostas das entidades conforme às pressões institucionais que delineiam os rumos do ambiente mercadológico. Apesar disso, a Teoria Institucional não se preocupa com as ações e os interesses dos atores sociais, sendo uma de suas principais críticas (Leonel \& Cunha, 2013; Scott, 2001).

No campo das finanças, há indícios de que a identificação da relação entre aspectos financeiros e a Teoria Institucional foi intensificada no século XXI. Os estudos que discutem essa relação têm como principais temas financeiros: Governança Corporativa (Ntim \& Soobaroyen, 2013), estrutura de capital (Driffield, Mickiewicz \& Temouri, 2014), investimentos (Kwabi, Boateng, \& Adegbite, 2018), fusões e aquisições (Du, Boateng \& Newton, 2015), finanças culturais (Goodell, 2019), implicações do gerenciamento de resultados (Eng et al., 2019) e análise e mensuração de desempenho (Almeida \& Callado, 2017).

\section{Procedimentos Metodológicos}


Para a realização do presente estudo, foi utilizada como estratégia de pesquisa a Revisão Sistemática da Literatura (RSL) de caráter qualitativo. Esse modelo de revisão permite reunir e articular informações de pesquisas anteriores separadamente e gerar resultados mais críticos e robustos. Além da robustez que a RSL propõe, é possível identificar novos temas e lacunas para estudos posteriores.

Nesse sentido, realizou-se uma RSL dos artigos que utilizaram a Teoria Institucional como plataforma teórica para pesquisas no campo das finanças. 0 período de análise foi definido de maneira tempestiva, isto é, abrange todo o período de publicações das revistas selecionadas. As variáveis utilizadas como procedimento metodológico foram baseadas em estudos de Moll, Burns e Major (2006); Chenhall e Smith (2011) e Soeiro e Wanderley (2019). As referidas pesquisas realizaram revisões sistemáticas no campo da contabilidade e que podem ser replicadas para o campo das finanças, devido à proximidade das áreas.

Nos periódicos nacionais, utilizou-se os listados no Qualis Capes, na área de conhecimento em Administração, Ciências Contábeis e Turismo na avaliação do quadriênio 2013-2016. A seleção dos periódicos envolveu a utilização dos termos "finanças" ou "finance" ou "finanzas" nos estratos A1, A2, B1 e B2. Os achados mostram apenas três periódicos com esses estratos, sendo: Revista Contabilidade \& Finanças (A2); Revista Brasileira de Finanças (B1) e Revista de Gestão, Finanças e Contabilidade (B2).

Para os periódicos internacionais, utilizou-se o Combined Journal Guide da Association of Business Schools (ABS, 2018) com a categoria Finance, a fim de identificar os períodos voltados para o campo das finanças. A partir da utilização das grades mais elevadas, ou seja, 4 e 3, foram selecionados 37 periódicos, mas apenas 7 possuem artigos com a base teórica composta pela Teoria Institucional de maneira isolada ou combinada com outra teoria. De acordo com os critérios, o único periódico selecionado na grade 4 foi o Journal of Financial Economics. Os periódicos da grade 3 foram: Corporate Governance: An International Review; European Journal of Finance; International Journal of Finance and Economics; International Review of Financial Analysis; Journal of Banking \& Finance; Journal of International Financial Markets, Institutions \& Money; Review of Quantitative Finance and Accounting.

Os critérios de seleção, tanto de periódicos nacionais quanto internacionais, visam buscar artigos de alto impacto e que sejam especializados no campo das finanças. A escolha por periódicos especializados é para garantir que haja um maior alinhamento na avaliação dos artigos em finanças, bem como evitar que os artigos façam paralelo indissociável com outros campos do conhecimento.

Foram examinados 65 artigos com o período que abrange todo o escopo de publicações das revistas selecionadas, sendo doze brasileiros e 45 internacionais. Foi realizada a leitura integral das pesquisas para garantir que os estudos estivessem alinhados com o objetivo da presente pesquisa. Desses, foram selecionados quatro brasileiros e 28 internacionais, sendo excluídos 33 por não atender os critérios de: estar relacionado ao campo das finanças e utilizar a Teoria Institucional como base teórica. A análise da base teórica nos artigos pesquisados foi fundamentada em declaração explícita no corpo do texto ou se a Teoria Institucional foi utilizada para embasar a discussão dos resultados. 0 detalhamento da seleção dos artigos pode ser visualizado na Figura1.

As linhas de pesquisa foram categorizadas de maneira tempestiva, sendo alocadas de acordo com tema da pesquisa analisada. Em outras palavras, a relação das linhas de pesquisas foram observadas a partir da literatura revisada Encontraram-se pesquisas em governança corporativa, estrutura de capital, investimentos, fusões e aquisições, finanças culturais, implicações do gerenciamento de resultados e análise e mensuração de desempenho. Além de quantificá-los de acordo com o número de publicações/ano/periódico, também foi possível analisar a linha de pesquisa de maneira mais aprofundada, buscando direcionamentos, avanços, limitações, lacunas, pontos não explorados ou que ainda não alcançaram saturação teórica.

\section{Apresentação dos Resultados}

\subsection{Breve Análise Descritiva dos Resultados}

Ao que tange as vertentes da Teoria Institucional (Tabela 1), a Nova Sociologia se destacou, seguido da Velha Economia. Resultado semelhante foi encontrado na RSL de Soeiro e Wanderley (2019) que analisou o uso da Teoria Institucional na pesquisa em contabilidade. A vertente multi-teórica engloba aspectos da nova sociologia, velha economia e nova economia, sendo presente em quase metade das pesquisas.

Figura 1 - Descrição e refinamento da pesquisa 


\begin{tabular}{|c|c|c|c|}
\hline Questão Problema & \multicolumn{3}{|c|}{$\begin{array}{l}\text { Quais os avanços e tendências dos estudos em finanças que estão utilizando a Teoria } \\
\text { Institucional como base teórica? }\end{array}$} \\
\hline $\begin{array}{l}\text { Estratégia de } \\
\text { Pesquisa }\end{array}$ & \multicolumn{3}{|c|}{ Revisão Sistemática Qualitativa da Literatura } \\
\hline Veículo de Pesquisa & \multicolumn{3}{|c|}{ Periódicos online } \\
\hline Fonte de Pesquisa & \multicolumn{3}{|c|}{$\begin{array}{l}\text { Periódicos Nacionais A1 a B2 - Qualis/Capes 2013-2016; } \\
\text { Periódicos Internacionais com grades } 4 \text { e } 3 \text { do Guia Com bined Journal } \\
\text { Guide da Association of Business Schools - } 2018\end{array}$} \\
\hline \multirow{2}{*}{$\begin{array}{l}\text { Palavras de Busca } \\
\text { para artigos }\end{array}$} & 3 Periódicos Nacionais & 37 Periódicos Internacionais & 4 \\
\hline & \multicolumn{3}{|c|}{$\begin{array}{l}\text { Teoria Institucional; } \\
\text { Institutional Theory }\end{array}$} \\
\hline \multirow[b]{2}{*}{ Artigos Coletados } & \multirow[t]{2}{*}{ eriódicos Nacionais } & 7 Periódicos Internacionais & \\
\hline & & 53 Artigos & \\
\hline \multirow[b]{2}{*}{$\begin{array}{c}\text { Critérios para } \\
\text { Análise dos Artigos }\end{array}$} & $\downarrow$ & $\downarrow$ & \\
\hline & \multicolumn{2}{|c|}{$\begin{array}{l}\text { Artigo utiliz ou da Teoria Institucional com o ba se para discussã o; } \\
\text { Artigo vincula do a o cam po dasfinanças. }\end{array}$} & \\
\hline $\begin{array}{l}\text { Amostra Final de } \\
\text { Artigos }\end{array}$ & 4 Artigos Nacionais & 28 Artigos Internacionais & \\
\hline
\end{tabular}

Fonte: dados da pesquisa (2021)

Tabela 1 - Frequência de artigos com Teoria Institucional por corrente da teoria

\begin{tabular}{|c|c|c|c|c|c|c|c|c|c|c|c|c|c|c|c|}
\hline Vertente & $\begin{array}{l}20 \\
04\end{array}$ & $\begin{array}{l}20 \\
08\end{array}$ & $\begin{array}{l}20 \\
09\end{array}$ & $\begin{array}{l}20 \\
10\end{array}$ & $\begin{array}{l}20 \\
12\end{array}$ & $\begin{array}{l}20 \\
13\end{array}$ & $\begin{array}{l}20 \\
14\end{array}$ & $\begin{array}{l}20 \\
15\end{array}$ & $\begin{array}{l}20 \\
16\end{array}$ & $\begin{array}{l}20 \\
17\end{array}$ & $\begin{array}{c}201 \\
8\end{array}$ & $\begin{array}{l}20 \\
19\end{array}$ & $\begin{array}{c}202 \\
0\end{array}$ & Total & $\begin{array}{c}\text { Total } \\
\%\end{array}$ \\
\hline Multi-teórica & & & & 1 & & 1 & 3 & 3 & 1 & & 2 & & 5 & 16 & $50 \%$ \\
\hline $\begin{array}{c}\text { Nova } \\
\text { Sociologia } \\
\text { Institucional } \\
\text { (NIS) }\end{array}$ & 1 & 2 & & 1 & & & & & & 1 & 1 & & 1 & 7 & $22 \%$ \\
\hline $\begin{array}{c}\text { Velha } \\
\text { Economia } \\
\text { Institucional } \\
\text { (OIE) }\end{array}$ & & 1 & 1 & & 1 & & & & 1 & & 1 & & 1 & 6 & $19 \%$ \\
\hline
\end{tabular}




\begin{tabular}{c|c|c|c|c|c|c|c|c|c|c|c|c|c|c|c}
\hline $\begin{array}{c}\text { Nova } \\
\text { Economia } \\
\text { Institucional } \\
\text { (NIE) }\end{array}$ & & & & & & & & & & & & & & & \\
\hline Total & 1 & 3 & 1 & 2 & 1 & 2 & 3 & 3 & 2 & 1 & 5 & 1 & 7 & & $9 \%$ \\
\hline Total \% & $3 \%$ & $9 \%$ & $3 \%$ & $6 \%$ & $3 \%$ & $6 \%$ & $9 \%$ & $9 \%$ & $6 \%$ & $3 \%$ & $16 \%$ & $3 \%$ & $22 \%$ & 32 & $100 \%$ \\
\hline
\end{tabular}

Fonte: dados da pesquisa (2021)

Ainda no âmbito da multi-teórica, percebe-se que a maior parte dos estudos utilizam a Teoria Institucional em conjunto com outras teorias, como, por exemplo, a Teoria da Sinalização, a Teoria da Agência e a Teoria dos stakeholders. Outro ponto importante é a proximidade dos resultados da nova sociologia institucional e a velha economia, sendo ambos distribuídos nos anos 2008 a 2010 e de 2016 a 2020.

Nas linhas de pesquisa (Tabela 2), a maioria dos estudos são em governança corporativa, seguido por mensuração e divulgação do desempenho e risco, decisões de investimento e financiamento. 0 destaque da governança pode ser explicado pela área que mais envolve conceitos da Teoria Institucional como normas e legitimidade dos stakeholders. As outras linhas parecem estar em processo embrionário quanto a utilização da Teoria Institucional, o que dá margem para novas pesquisas.

Tabela 2 - Artigos com Teoria Institucional por linha de pesquisa

\begin{tabular}{|c|c|c|c|c|c|c|c|c|c|c|c|c|c|c|c|}
\hline $\begin{array}{l}\text { Linha de } \\
\text { pesquisa }\end{array}$ & $\begin{array}{l}20 \\
04\end{array}$ & $\begin{array}{l}20 \\
08\end{array}$ & $\begin{array}{l}20 \\
09\end{array}$ & $\begin{array}{l}20 \\
10\end{array}$ & $\begin{array}{l}20 \\
12\end{array}$ & $\begin{array}{l}20 \\
13\end{array}$ & $\begin{array}{l}20 \\
14\end{array}$ & $\begin{array}{l}20 \\
15\end{array}$ & $\begin{array}{l}20 \\
16\end{array}$ & $\begin{array}{l}20 \\
17\end{array}$ & $\begin{array}{c}201 \\
8\end{array}$ & $\begin{array}{l}20 \\
19\end{array}$ & $\begin{array}{c}202 \\
0\end{array}$ & Total & $\begin{array}{c}\text { Total } \\
\%\end{array}$ \\
\hline $\begin{array}{l}\text { Governança } \\
\text { Corporativa }\end{array}$ & 1 & 2 & & 2 & & 1 & 3 & 1 & 2 & & 2 & 1 & 3 & 18 & $56 \%$ \\
\hline $\begin{array}{c}\text { Mensuração \& } \\
\text { divulgação do } \\
\text { desempenho }\end{array}$ & & & 1 & & 1 & 1 & & & & 1 & & & & 4 & $13 \%$ \\
\hline $\begin{array}{c}\text { Fusões \& } \\
\text { Aquisições }\end{array}$ & & & & & & & & & & & & & 2 & 2 & $6 \%$ \\
\hline $\begin{array}{l}\text { Finanças } \\
\text { Culturais }\end{array}$ & & 1 & & & & & & & & & 1 & & 1 & 3 & $9 \%$ \\
\hline $\begin{array}{l}\text { Risco, decisões } \\
\text { de } \\
\text { investimento e } \\
\text { financiamento }\end{array}$ & & & & & & & & 2 & & & 1 & & 1 & 4 & $13 \%$ \\
\hline $\begin{array}{l}\text { Implicações do } \\
\text { gerenciamento } \\
\text { de resultados }\end{array}$ & & & & & & & & & & & 1 & & & 1 & $3 \%$ \\
\hline Total & 1 & 3 & 1 & 2 & 1 & 2 & 3 & 3 & 2 & 1 & 5 & 1 & 7 & \multirow{2}{*}{32} & \multirow{2}{*}{$100 \%$} \\
\hline Total \% & $3 \%$ & $9 \%$ & $3 \%$ & $6 \%$ & $3 \%$ & $6 \%$ & $9 \%$ & $9 \%$ & $6 \%$ & $3 \%$ & $16 \%$ & $3 \%$ & $22 \%$ & & \\
\hline
\end{tabular}

Fonte: dados da pesquisa (2021)

Com a breve análise descritiva dos resultados, observa-se a pluralidade de pesquisas com diferentes correntes da Teoria Institucional e aplicação em diferentes linhas de pesquisas em finanças. Ainda assim, nota-se que a Teoria Institucional, na maioria das vezes, é utilizada aliada a outra teoria, sendo um dos instrumentos de suporte para as discussões. A seguir serão exploradas, de maneira mais específica, as linhas e temas de pesquisas em finanças, a fim de apresentar como essa teoria está sendo utilizada e os avanços nas investigações do campo. 


\subsection{Apresentação dos estudos por linha de pesquisa}

\subsubsection{Governança Corporativa}

A maioria dos estudos em finanças que utilizam a Teoria Institucional faz parte da linha de pesquisa em governança corporativa. As instituições funcionam como esferas sociais distintas que diferem entre ambientes. Nas instituições, existem instituições menores, como, por exemplo, setores ou níveis hierárquicos. Diferentes instituições externas ou internas podem ter interesses distintos e podem surgir "arenas", onde surge o conflito e o desalinhamento de interesses.

Driffield, Mickiewicz e Temouri (2014) combinaram a Teoria da Agência e a Institucional para explicar a divisão das ações entre os investidores estrangeiros (maioria) e locais (minoritários). A estrutura de propriedade deve ser gerida para que atenda o interesse de todos os acionistas, mas é preciso levar em consideração o ambiente institucional. Para tal, é preciso controlar internamente os efeitos da legislação do país anfitrião e os atributos do ambiente institucional devem ser instrumentados, pois instituições fracas levam à concentração de propriedade e deixam o nível de ações minoritárias sem poder.

Nguyen, Locke e Reddy (2015) analisaram a relação entre concentração de propriedade e desempenho financeiro de empresas em Cingapura e Vietnã. 0 enfoque em dois tipos diferentes de sistemas de governança (bem desenvolvidos vs. subdesenvolvidos) permitiu analisar a qualidade da governança em nível nacional. Eles concluíram que os efeitos do desempenho dos mecanismos internos de governança corporativa são específicos de cada país e afetam o desempenho da empresa. Além disso, sugerem que a eficácia dos mecanismos de governança depende de fatores institucionais e características ambientais.

Os efeitos de sinalização das políticas anti má conduta na avaliação de mercado, aliado aos mecanismos internos de governança corporativa e ambientes institucionais externos, foram alvo de investigação de Li et al., (2017). Os resultados mostram que mecanismos eficazes de governança corporativa levam a políticas anti má conduta de maior qualidade, embora por si só não afetem a avaliação do mercado em geral, mas melhoram sua avaliação em países com ambientes legais e regulatórios mais fortes. (Li et al., 2017).

Ntim, Lindop e Thomas (2013) examinaram se a qualidade da governança corporativa tem algum efeito sobre as Divulgações de Risco Corporativo (DRC) na África do Sul com foco particular no pré e pós-períodos de crise financeira global de 2007/2008. A adoção voluntária do DRC é dada à particularidade de cada contexto corporativo e melhora a qualidade da divulgação ao longo do tempo. Ntim, Lindop e Thomas (2013) defendem que as autoridades regulatórias podem melhorar o relatório de risco ao incentivar empresas a divulgar mais informações de risco orientadas para o futuro, que atenda a um limite mínimo de relevância e confiabilidade para os interessados.

As organizações se institucionalizaram e buscam ser mais valorizadas ao se preocuparem com sua própria manutenção. Chakrabarty e Bass (2014) utilizaram a Teoria Institucional para examinar a governança corporativa em instituições de microfinanças (IMFs), mais precisamente, e investigaram a relação entre a composição dos conselhos e a capacidade das IMFs de enfrentar espaços institucionais para garantir a viabilidade organizacional. As crises podem agravar os espaços institucionais e, consequentemente, prejudicar a orientação estratégica da empresa. No entanto, uma organização pode preencher as lacunas com instrumentos de governanças eficientes, como, por exemplo, a composição do conselho. 0 papel do conselho além de preencher essas lacunas, pode usar instrumentos para propor soluções que ajudem o desenvolvimento organizacional.

A composição do conselho também tem destaque com a Teoria Institucional, geralmente relacionada à tentativa de as empresas conquistarem legitimação e serem valoradas. Buallay et al., (2020) examinaram a relação entre a diversidade de gênero no conselho e os relatórios sustentáveis. Os stakeholders financeiros (investidores, acionistas, credores ou devedores) tendem a ganhar com a institucionalização do relato de sustentabilidade, pois refletem os diferentes níveis de eficiência alcançados nas decisões de investimento e financiamento. Além disso, em países que levam a sério a igualdade de gênero, as empresas tendem a abordar as questões de diversidade mais facilmente. Tal abordagem funciona para que a firma seja reconhecida e legitimada pela sociedade.

A revisão sistemática de Nguyen, Ntim e Malagila (2020) pesquisou sobre mulheres em conselhos de administração e o desempenho financeiro, e não financeiro corporativo. A ausência ou presença de mulheres não depende das instituições em nível nacional, empresarial, social e individual. Em outras palavras, a perspectiva institucional explícita que diferenças nas regras, normas, procedimentos, ambientes e requisitos das empresas podem explicar as diferenças na nomeação de mulheres como diretoras e suas respectivas remunerações. 
A criação de códigos de boas práticas de governança contribui para que os interesses de todos os stakeholders sejam alinhados. Uma dessas práticas de alinhamento de interesse são as remunerações dos executivos. O objetivo da pesquisa de Bender (2004) foi verificar como os participantes do processo de fixação de remuneração veem o uso da remuneração por desempenho. Bender (2004) encontrou que as empresas listadas no Reino Unido usam Recompensas Baseada ao Desempenho (PRP) de seus executivos e essa prática está se tornando uma tendência. Com base na Teoria Institucional, a pesquisa trouxe evidências de que tanto o isomorfismo coercitivo quanto o mimético fazem com que as empresas usem o PRP e se preocupem para que esse plano de remuneração seja legítimo para os stakeholders. Além de ser uma prática do mercado, influencia as empresas a buscarem por legitimidade e atrair e reter bons executivos.

Questões sociais e ambientais também podem influenciar as remunerações. Ikram, Li e Minor (2019) analisaram por que as empresas oferecem remuneração contingente à Responsabilidade Social Corporativa (RSC) e as condições sob as quais essa remuneração melhora o desempenho social corporativo. Apesar da literatura mostrar que há evidências que a RSC pode, assim como não, afetar o desempenho da organização, a promoção de RSC por muitas vezes é de fachada, por isso a necessidade de relatar informações à sociedade e verificar se está alcançando legitimidade. A imprensa popular e os profissionais têm defendido e feito pressão para que as empresas vinculem a remuneração de seus executivos ao cumprimento das metas de RSC, evitando o seu uso de fechada e tentando atender às expectativas dos stakeholders

A sociedade em si também demanda das empresas responsabilidade social corporativa e sustentabilidade. A institucionalização é resultado da interação e adaptação do pensar coletivo, e esse pensar, quando incorporado pelas organizações, fornece valor intrínseco. Além disso, permite que as organizações sejam aceitas e aumentam as probabilidades de sobrevivência, em que, antes da institucionalização, as empresas tinham apenas a utilidade instrumental.

Em um tema similar, Nandy et al., (2020) investigaram o impacto das redes de diretores nas atividades de RSC. Os stakeholders (investidores, clientes, meio ambiente, sociedade, etc.) realizam pressões na condução do negócio para que as organizações sinalizem sua responsabilidade de longo prazo. Essas indicações positivas no mercado permitem que as empresas tenham uma imagem corporativa melhor e isso motiva as empresas a investir mais em atividades de RSC financeiramente viáveis. Ao investir em atividades de RSC, as empresas podem evitar punições severas por parte de órgãos reguladores ou até mesmo boicotes pela sociedade por não considerarem a abordagem sustentável nos negócios.

As características institucionais das organizações podem ser moldadas por forças externas. Algumas dessas forças são o Estado, o ambiente jurídico, as convenções e a própria sociedade. Jacoby et al., (2019) investigaram como a governança corporativa interna, o monitoramento externo e o ambiente jurídico e de negócios afetam, em conjunto, a eficácia gerencial de uma empresa na transparência das informações ambientais em um cenário internacional. A conclusão é que os mecanismos internos de governança aumentam a transparência em relação aos danos ambientais e o fazem indiretamente por meio de mecanismos de controle externo. 0 ambiente jurídico e o mercado moderam a transparência de informações ao exercer pressões para as empresas e a Teoria Institucional reforça que as empresas buscam legitimidade ao tentar melhorar seu desempenho em relação às questões ambientais.

A remuneração também pode ser padronizada, ou não, por fatores externos. Chizema (2008) buscou entender o porquê da divulgação da remuneração individual dos executivos, baseada no Código Alemão de Governança Corporativa, encontrou resistência em algumas empresas, ao mesmo tempo que foi uma inovação bem-vinda para outras. Com uma perspectiva neoinstitucional, utilizar o campo organizacional como unidade de análise ajuda explicar o porquê de o modelo de remuneração é aceito por umas organizações e resistido por outras no mesmo ambiente ou contexto institucional. Dessa forma, atores organizacionais têm interesses e poderes distintos, e utilizam suas capacidades para moldar os eventos. Logo, a Teoria Institucional e a Teoria da Sinalização mostram que os acionistas perceberão a divulgação da remuneração individual como compromisso de uma empresa com o valor, reputação e legitimidade, atraindo, assim, mais recursos (Chizema,2008).

Judge et al., (2010) buscaram compreender os antecedentes do ativismo de acionistas direcionado a empresas localizadas em três países de direito consuetudinário (EUA, Reino Unido e Austrália) e três países de direito civil (Japão, Alemanha e Coreia do Sul). Enquanto o ativismo financeiro é mais forte nos sistemas jurídicos de direito consuetudinário, o ativismo social é mais forte em ambientes com maior desigualdade de renda. A Teoria Institucional resguarda o ativismo social, devido ao foco na legitimidade social, ao invés de maximização da riqueza econômica.

Yamahaki e Frynas (2016) investigaram até que ponto a regulamentação incentiva atitudes e comportamentos de engajamento de acionistas privados sobre questões ambientais, sociais e de 
governança corporativa no Brasil e na África do Sul. A legislação incentiva o envolvimento dos acionistas de modo indireto, mas é importante destacar o isomorfismo normativo da legislação governamental em termos de endossar e facilitar mudanças no comportamento do investidor (Yamahaki \& Frynas, 2016). As pressões indiretas sinalizam e moldam o comportamento das organizações, por vezes, sem a necessidade de regulamentação formal.

O objetivo do artigo de Zattoni e Cuomo (2008) foi investigar se a principal razão por trás da proliferação dos códigos de governança em países de direito civil é: (i) a determinação de melhorar a eficiência dos sistemas de governança nacional; ou (ii) a vontade de "legitimar" as empresas nacionais no mercado financeiro global sem melhorar radicalmente as práticas de governança. Os países que são aportados pelo direito consuetudinário forneceram legitimidade para a inovação e maior utilização dos códigos de governança, enquanto os países de direito civil são adotantes tardios, apesar da pressão para implementar as reformas por medo de perder a legitimidade.

A divulgação das práticas de governança corporativa das companhias do setor bancário da BM\&FBovespa, segundo as recomendações do Código do IBGC, foi alvo das análises de Moura et al., (2014). Nos resultados, todas as empresas divulgaram a remuneração dos conselheiros, devido à instrução CVM 480 de 2009, que estabelece a obrigatoriedade da remuneração dos conselheiros e executivos. Dois bancos da amostra foram os que mais se destacaram entre os que mais divulgaram informações. Moura et al., (2014) argumentam que por esses bancos terem ações negociadas na Bolsa de Valores de Nova York, há maiores exigências de governança corporativa e maior transparência para atrair investidores estrangeiros.

Johanson e Østergren (2010) discutiram sobre os antecedentes da "norma de independência do conselho" (BIN) ao realizarem uma análise comparativa dos sistemas de governança da Suécia e do Reino Unido. Por se tratar de dois países, variáveis exógenas são distintas e há pressão para atender às melhores práticas de governança, pois a perspectiva neoinstitucional aliada à governança corporativa insere contextos econômicos, culturais e sociais. Johanson e Østergren (2010) mostram que o BIN, em países menores, como a Suécia, seguem códigos de melhores práticas influentes por razões de legitimidade e os grupos de interesse, como investidores institucionais estrangeiros, exercem pressão sobre os normatizadores nacionais.

Matos et al., (2018) analisaram se há diferença de posicionamento entre os auditores e os reguladores na última fase de consulta pública do projeto Improving the Auditor's Report, pertencente ao International Auditing and Assurance Standards Board (IAASB), na tentativa de influenciar a normatização da atividade de auditoria, bem como avaliar a efetividade da estratégia de submissão de cartas-comentário por parte desses grupos de interesse. Nos resultados, os grupos de auditores atuaram para influenciar o regulador a conciliar diferentes interesses ao lidar com a possibilidade de $o$ auditor deliberar para que não haja assuntos críticos a reportar, e das declarações relacionadas à GC da companhia auditada. Ainda assim, o IAASB sujeitou-se às pressões no desenvolvimento de normas de auditoria, garantindo a legitimidade à sua posição de órgão normatizador.

De maneira geral, a Teoria Institucional é uma teoria sólida no âmbito da governança corporativa. Tal afirmação pode ser justificada pela quantidade de artigos em finanças que possuem a linha de governança sendo publicados com base na Teoria Institucional. Além disso, quanto mais se pesquisa em governança, mais surgem lacunas. Algumas opções de estudos futuros podem ser: analisar o impacto do ambiente de governança nacional no ativismo dos acionistas, a interação de mecanismos internos e externos de GC em contextos institucionais diferentes como, por exemplo, economias desenvolvidas e emergentes. Uma outra possibilidade de pesquisa sugerida é verificar se o contexto institucional interno e externo estimula ou restringe o envolvimento dos acionistas.

\subsubsection{Mensuração e Divulgação do Desempenho}

As práticas da gestão de desempenho se traduzem no exercício do poder, pois analisam como as organizações estão sobrevivendo e alcançando seus objetivos, a fim de chamar a atenção do mercado e dos stakeholders. Apesar da importância, a institucionalização de mensuração e divulgação de desempenho ainda possui um pequeno número de estudos em finanças com apoio da Teoria Institucional.

Russo et al., (2012) analisaram a obra "A Estratégia em Ação - Balanced Scorecard", ao buscar termos expressos na obra para identificar evidências que possam contribuir com o processo de institucionalização do BSC pelas empresas. Nos resultados da pesquisa, o estágio pré-institucional do BSC foi o nível menos identificado ao mencionar as motivações para utilização da ferramenta. Posteriormente, o nível semi-institucional trouxe o processo de monitoramento, teorização e a difusão da ferramenta. Na institucionalização total foram categorizados em impactos positivos, resistências de grupos, defesas de grupos (o papel dos agentes). Por fim, a categoria de legitimidade e legitimação abrange todos os níveis de institucionalização e representa a maioria dos achados. A análise realizada 
sobre a obra permitiu compreender a obtenção da legitimidade do BSC, influenciando e sustentando a decisão pela adoção de tal metodologia pelas organizações.

A adoção de práticas de RSC na GC pode afetar o desempenho das organizações. Ntim e Soobaroyen (2013) investigaram a relação entre GC e RSC e como a GC pode influenciar positivamente o desempenho financeiro corporativo (CFP) e RSC. Por meio da estrutura neoinstitucional, Ntim e Soobaroyen (2013) mostraram como as empresas com melhores práticas de governança têm maior probabilidade de buscar uma agenda mais socialmente responsável que enfatiza os efeitos de eficiência e legitimação das práticas de RSC. Além disso, a eficiência e a legitimação coexistem e refletem as relações multifacetadas entre a empresa e seus stakeholders.

Almeida e Callado (2017) identificaram características isomórficas na divulgação de indicadores de desempenho sociais e ambientais de empresas do setor de energia elétrica. Os achados mostram o baixo percentual de relatórios que contêm informações sobre indicadores ambientais e sociais, apesar da existência de legislação nacional. Por outro lado, foi observado uma tendência ao reportar indicadores essenciais em detrimento dos adicionais, devido ao fato de os indicadores essenciais são aplicados à maioria das organizações, enquanto os adicionais não (Almeida \& Callado, 2017).

Zattoni, Pedersen e Kumar (2009) exploraram a ligação entre o desempenho da empresa e a evolução do ambiente institucional e concluíram que quando os mercados de trabalho, capitais e produtos são caracterizados por grandes imperfeições e instituições de apoio fracas, grupos de negócios superam empresas independentes. Por outro lado, quando os mercados e as instituições são mais fortes, as empresas afiliadas ao grupo deixam de mostrar um desempenho superior. Isso sugere que o desempenho está associado ao contexto institucional e suas características particulares.

Diante de novos sistemas de mensuração, avaliação e divulgação do desempenho, surgem novas lacunas. A questão da legitimidade e da convenção surge em contexto global com a difusão dos valores e das regras. A ênfase muda das propriedades para prescrições racionalizadas, podendo ser utilizadas ou rejeitadas por diferentes grupos. 0 desempenho pode contribuir para a legitimidade, recursos e capacidades de sobrevivência. Como sugestão de pesquisas, recomenda-se verificar quais as medidas de desempenho mais utilizadas pelas organizações e como essas medidas afetam a captação de recursos ou o nível de investimento. Do mesmo modo, se a prática de mensuração e divulgação de desempenho difere entre países de direito civil ou consuetudinário.

\subsubsection{Fusões \& Aquisições}

Os arranjos institucionais são específicos de cada região e são produtos das interações sociais. Esses arranjos são moldados pelo contexto social em que as organizações atuam. No caso das fusões e aquisições (F\&A), características ambientais e institucionais vão influenciar no sucesso ou fracasso da F\&A, como, por exemplo, eficiência dos mercados, controle corporativo, transparência de informações, competição, liquidez, dentre outros.

Attah-Boakye et al., (2020) analisaram negócios de fusões e aquisições (M\&A) que foram cancelados, com ênfase à liberdade econômica e ao ambiente jurídico dos países. A Teoria Institucional embasa que o fracasso ou sucesso dos negócios de M\&A é influenciado pelo ambiente institucional dos países de origem, como, por exemplo, liberdade econômica e barreiras de entradas de novos concorrentes. Além disso, geralmente existem pressões externas e pressões institucionais que influenciam as fusões e aquisições, justamente pela necessidade de sobrevivência das organizações.

Ao analisar os efeitos da distância institucional formal e informal no desempenho de fusões e aquisições internacionais de curto e longo prazo das empresas, Li et al., (2020) perceberam que essas distâncias trazem impactos negativos no desempenho de fusões e aquisições internacionais de curto prazo, mas um resultado positivo a longo prazo. Novamente é possível perceber o impacto da Teoria Institucional ao concluir que é melhor realizar F\&A em países com PIB mais baixo e maior competitividade no curto prazo, pois geralmente os ativos são subestimados. No longo prazo, é melhor conduzir fusões e aquisições em países com maior PIB e menor competitividade, devido à existência de grandes mercados e pouca competitividade. Consequentemente, o ambiente institucional seleciona os mais aptos de acordo com sua adaptabilidade para sobreviver em um mercado cada vez mais amplo e competitivo.

Existem poucos estudos na literatura de fusões e aquisições que aproveitam a Teoria Institucional como base teórica. Os achados mostram que os estudos são pautados em fusões e aquisições de níveis interfronteiriços, dando margem para estudos em níveis nacionais. Outra possibilidade de estudo está relacionada às fusões e aquisições em que os ambientes culturais são diferentes ou até mesmo em regiões regidas pelo direito civil versus consuetudinário.

\subsubsection{Finanças Culturais}


A linha de pesquisa em finanças culturais é algo recente na literatura e possui similaridades com a Teoria Institucional. Muitos modelos de negócios não conseguem se adaptar em outras nações, devido à distinção de realidades culturais. Considerando que diferenças culturais influenciam o desempenho das firmas, as organizações precisam adaptar seus comportamentos para que estejam em conformidade com os valores locais e consigam ser legitimadas.

Goodell (2019) realizou um levantamento da literatura em finanças culturais, analisando como alguns resultados podem ser enquadrados em relação ao institucionalismo normativo ou à racionalidade pretendida. Li e Harrison (2008) analisaram como e em que medida a cultura nacional influencia a composição e a estrutura de liderança dos conselhos de administração de empresas multinacionais. Por fim, Boateng et al., (2020) examinaram o impacto da GC na corrupção com base na Teoria Institucional e concluem que a CG e a cultura nacional explicam o nível de corrupção entre as sociedades.

Sabendo que a corrupção possui aspectos socioeconômicos e depende dos ambientes / institucionais, a Teoria Institucional permite coletar aspectos sociais associados à corrupção em nível nacional ou internacional. 0 uso da Teoria Institucional para analisar a interação entre a composição do conselho e o ambiente cultural permite uma visão que transcende fronteiras nacionais, e, mesmo com a globalização dos mercados, as características institucionais do país de origem têm poder e influência na composição do conselho. Logo, as normas sociais, conforme refletidas nas dimensões culturais nacionais, moldam a legitimidade das estruturas de governança corporativa (Li \& Harrison, 2008). Ainda assim, os estudos de finanças culturais são examinados comparando a cultura nacional como influenciadores dos sistemas financeiros, de modo a impactar os incentivos para que os atores maximizem suas utilidades.

Por ainda não ser uma área consolidada e amplamente conhecida, existe a dificuldade de as Finanças Culturais serem reconhecidas por pesquisadores, mas isso não impede que sejam realizados estudos que relacionem a cultura, a Teoria Institucional e o campo das finanças. Algumas sugestões de pesquisas podem ser direcionadas a analisar como a cultura pode explicar a composição do conselho de governança, influenciar na remuneração de executivos ou interferir nas práticas de RSC ou sustentabilidade das firmas.

\subsubsection{Risco, Decisões de Investimento e Financiamento}

As organizações estão modificando a maneira como identificam e gerenciam os riscos ao incorporar novas normas, regras, informações e práticas de natureza externa que levam tempo para se tornarem institucionalizadas. Conjuntamente, as avaliações de alternativas de investimentos e financiamentos incorporam regras externas formais e informações institucionais no processo de tomada de decisão. A Teoria Institucional permite compreender os fatores que influenciam as decisões de investimento e financiamento e o gerenciamento de riscos empresariais.

A estrutura de vencimento da dívida corporativa na região do MENA e seus determinantes institucionais foram alvos da pesquisa de Awartani (2016). A conclusão é que organizações com ambientes institucionais mais robustos utilizam mais dívida de longo prazo, pois, em um ambiente jurídico mais forte, existe maior proteção aos credores e intermediários financeiros. Nessas condições, os credores e agentes intermediários tendem a estender o crédito para o longo prazo, devido a maior segurança jurídica.

Derouiche, Muessig e Weber (2020) examinaram o efeito da divulgação de risco sobre o número de analistas que seguem empresas listadas na bolsa. No contexto da Teoria Institucional, e sabendo que empresas com maior divulgação de risco atraem mais analistas financeiros, as empresas visam conquistar maior reputação com informações verídicas, independente se essas informações são positivas ou negativas. Além disso, sabendo que a empresa divulga mais informações, os custos de coleta para os analistas são menores e isso os incentiva a seguir essas empresas. A Teoria Institucional defende que a incorporação de normas permite obter maior aceitação social e sugere que as empresas que incorporam normas para obter aceitação social respeitam o valor do ambiente em que estão inseridas.

Kwabi, Boateng e Adegbite (2018) examinaram os efeitos da aplicação rigorosa das leis de insider trading, instituições e desenvolvimento do mercado de ações na alocação de portfólio de ações internacionais. Os fluxos de capital transfronteiriço dependem das características institucionais do país anfitrião que a aplicação das leis de insider trading, o nível das instituições e mercados afetam de maneira positiva os portfólios de ações internacionais. Logo, o ambiente institucional é crítico para as estratégias de investimento das empresas estrangeiras e decisões de alocação de portfólio internacional.

$\mathrm{Du}$, Boateng e Newton (2015) examinaram os efeitos da propriedade estatal das instituições e o comportamento de busca de recursos na China. O Estado e as instituições são fontes importantes de 
criação de valor de longo prazo para os adquirentes chineses, e a distribuição da riqueza pelo governo na forma de acesso privilegiado ao crédito a baixo custo aumenta o valor da empresa.

A literatura que relaciona riscos, decisões de investimentos e financiamentos com a Teoria Institucional ainda é modesta e lacunas podem ser identificadas. Novos estudos podem tratar da relação entre a interferência do ambiente jurídico na viabilidade de investimentos e financiamentos, como, também, podem verificar quais influências culturais contribuem para a definição dos riscos vivenciados pelas organizações.

\subsubsection{Implicações do Gerenciamento de Resultados}

Apesar da prática de gerenciamento de resultados ser alvo de pesquisa em contabilidade, as implicações desse gerenciamento podem ser alvo das pesquisas em finanças. Eng et al., (2019) compararam a prática do gerenciamento de resultados entre empresas familiares chinesas e empresas familiares dos EUA após a crise financeira de 2008. Enquanto a prática de gerenciamento de resultados é maior nos EUA em empresas familiares e nos períodos de pós-crise financeira, o contrário acontece na China.

Onde o contexto institucional é mais fraco, as empresas podem buscar mais legitimação e credibilidade com práticas de gerenciamento de resultados para melhorar sua imagem no mercado. Logo, a diferença do contexto institucional afeta o comportamento das empresas em relação às incertezas exógenas.

A literatura que alia a Teoria Institucional às implicações de gerenciamento de resultados é escassa, oferecendo diversas lacunas para pesquisas, por exemplo, verificar o impacto da cultura, do ambiente jurídico e da legitimidade das organizações nas práticas de gerenciamento de resultados frente ao mercado e a sociedade. Ainda assim, tal prática de gerenciamento pode trazer impacto no desempenho da empresa frente aos seus parceiros comerciais e investidores.

\section{Síntese dos Resultados}

As organizações estão inseridas num contexto de influências e prospecções em que possuem uma relação de retroalimentação com o ambiente externo. Essas organizações, além de influenciar o ambiente, também podem ser influenciadas pelo mesmo, no qual o ambiente molda suas estruturas e seus processos corporativos vigentes. Nessa dualidade, as características abordadas pela Teoria Institucional estão sendo utilizadas em discussões financeiras no meio acadêmico e corporativo. A partir do Quadro 1, aspectos relevantes, tendências e cenários de investigação em finanças podem ser identificados.

Quadro 1: Aspectos relevantes, tendências e cenários de investigação em finanças

\begin{tabular}{|c|c|c|c|}
\hline $\begin{array}{l}\text { Linhas de } \\
\text { pesquisa }\end{array}$ & Aspectos relevantes & Tendências & Cenários de investigação \\
\hline $\begin{array}{l}\text { Governança } \\
\text { Corporativa }\end{array}$ & $\begin{array}{c}\text {-O ambiente institucional } \\
\text { pode oferecer lacunas para } \\
\text { fomentar o conflito, assim } \\
\text { como solucioná-lo; } \\
\text { - Permite alterar os níveis } \\
\text { de divulgação de } \\
\text { informação; } \\
\text { - Fomenta práticas de } \\
\text { responsabilidade social } \\
\text { corporativa. }\end{array}$ & $\begin{array}{l}\text { - Análises das relações de } \\
\text { gênero e inclusão } \\
\text { feminina no ambiente } \\
\text { corporativo; } \\
\text {-Discussão da } \\
\text { remuneração e ativismos } \\
\text { dos conselhos e dos } \\
\text { executivos, bem como } \\
\text { divulgação de relatórios } \\
\text { estratégicos. }\end{array}$ & $\begin{array}{l}\text { - Estrutura de propriedade } \\
\text { - Independência e } \\
\text { composição do conselho; } \\
\text { - Governança em países de } \\
\text { direito civil e } \\
\text { consuetudinário. }\end{array}$ \\
\hline
\end{tabular}




\begin{tabular}{|c|c|c|c|}
\hline $\begin{array}{l}\text { Mensuração e } \\
\text { divulgação do } \\
\text { desempenho }\end{array}$ & $\begin{array}{c}\text { - As práticas da gestão de } \\
\text { desempenho traduzem-se } \\
\text { no exercício do poder; } \\
\text { - As normas podem } \\
\text { oferecer resistência à } \\
\text { aplicação de métodos de } \\
\text { mensuração; } \\
\text { - Características } \\
\text { isomórficas podem ser } \\
\text { encontradas na divulgação } \\
\text { de indicadores de } \\
\text { desempenho. }\end{array}$ & $\begin{array}{c}\text { - Divulgação de } \\
\text { informações adicionais } \\
\text { para legitimidade; } \\
\text { - Fomentar o uso de } \\
\text { ferramentas de } \\
\text { mensuração. }\end{array}$ & $\begin{array}{c}\text { - Adequação de } \\
\text { ferramentas de } \\
\text { mensuração ao ambiente } \\
\text { institucional; } \\
\text { - Relação do desempenho e } \\
\text { legitimidade }\end{array}$ \\
\hline $\begin{array}{c}\text { Fusões e } \\
\text { Aquisições }\end{array}$ & $\begin{array}{l}\text { - Ambiente institucional } \\
\text { pode elevar ou diminuir a } \\
\text { competitividade; } \\
\text { - Sobrevivência e seleção } \\
\text { das organizações em } \\
\text { ambiente competitivo; } \\
\text { - Os arranjos institucionais } \\
\text { são específicos de cada } \\
\text { região e são produtos das } \\
\text { interações sociais. }\end{array}$ & $\begin{array}{c}\text { - Influência das } \\
\text { características ambientais } \\
\text { e institucionais no } \\
\text { sucesso ou fracasso da } \\
\text { F\&A; } \\
\text { - Impacto assimétrico do } \\
\text { ambiente institucional no } \\
\text { desempenho de curto e } \\
\text { longo prazo. }\end{array}$ & $\begin{array}{l}\text { - Acordos cancelados de } \\
\text { fusões e aquisições; } \\
\text { - Efeitos da distância } \\
\text { institucional formal e } \\
\text { informal no desempenho } \\
\text { de fusões e aquisições. }\end{array}$ \\
\hline $\begin{array}{l}\text { Finanças } \\
\text { Culturais }\end{array}$ & $\begin{array}{l}\text { - As distintas realidades } \\
\text { culturais podem } \\
\text { influenciar aspectos } \\
\text { organizacionais; } \\
\text { - As organizações } \\
\text { precisam adaptar seus } \\
\text { comportamentos para que } \\
\text { estejam em conformidade } \\
\text { com os valores locais } \\
\text { - A cultura institucional } \\
\text { contribui para explicar a } \\
\text { corrupção. }\end{array}$ & $\begin{array}{c}\text { - Impacto da cultura na } \\
\text { formação do conselho; } \\
\text { - Normas sociais e sua } \\
\text { influência na legitimidade } \\
\text { das estruturas } \\
\text { organizacionais. }\end{array}$ & $\begin{array}{c}\text { - Estrutura de liderança; } \\
\text { - Normas sociais e cultura } \\
\text { nacional. }\end{array}$ \\
\hline $\begin{array}{l}\text { Risco, decisões } \\
\text { de investimento } \\
\text { e financiamento }\end{array}$ & $\begin{array}{l}\text { - As organizações estão } \\
\text { modificando a maneira } \\
\text { como identificam e } \\
\text { gerenciam os riscos ao } \\
\text { incorporar novas normas, } \\
\text { regras, informações e } \\
\text { práticas de natureza } \\
\text { externa; } \\
\text { - Normas e regras } \\
\text { estabelecem limites para o } \\
\text { endividamento } \\
\text { - Proteção aos credores } \\
\text { para diferentes níveis de } \\
\text { riscos. }\end{array}$ & $\begin{array}{c}\text { - As avaliações de } \\
\text { investimentos e } \\
\text { financiamentos } \\
\text { considerando regras } \\
\text { externas e informações } \\
\text { institucionais no processo } \\
\text { de tomada de decisão; } \\
\text { - Discussão dos ambientes } \\
\text { institucionais mais } \\
\text { robustos que utilizam } \\
\text { mais dívida de longo } \\
\text { prazo; } \\
\text { - O ambiente institucional } \\
\text { crítico para as estratégias } \\
\text { de investimento das } \\
\text { empresas estrangeiras e } \\
\text { decisões de alocação de } \\
\text { portfólio internacional. }\end{array}$ & $\begin{array}{l}\text { - Incorporação de normas; } \\
\text { - Dívida corporativa em } \\
\text { ambientes institucionais } \\
\text { robustos; } \\
\text { - Relação entre portfólios } \\
\text { de ações e leis de insider } \\
\text { trading, instituições e } \\
\text { desenvolvimento do } \\
\text { mercado de ações; } \\
\text { - Propriedade estatal das } \\
\text { instituições, } \\
\text { comportamento de busca } \\
\text { de recursos e os retornos } \\
\text { dos preços das ações. }\end{array}$ \\
\hline
\end{tabular}




\begin{tabular}{|c|c|c|c|}
\hline $\begin{array}{l}\text { Implicações do } \\
\text { gerenciamento } \\
\text { de resultados }\end{array}$ & $\begin{array}{c}\text { - As empresas podem } \\
\text { buscar mais legitimação e } \\
\text { credibilidade com práticas } \\
\text { de gerenciamento; } \\
\text { - Melhorar os resultados } \\
\text { para aprimorar a imagem } \\
\text { organizacional no } \\
\text { mercado. }\end{array}$ & $\begin{array}{l}\text { A diferença do contexto } \\
\text { institucional (mais forte } \\
\text { ou mais fraco) e sua } \\
\text { relação no } \\
\text { comportamento das } \\
\text { empresas diante das } \\
\text { incertezas exógenas e das } \\
\text { práticas de } \\
\text { gerenciamento. }\end{array}$ & $\begin{array}{c}\text { - Práticas do gerenciamento } \\
\text { de resultados em diferentes } \\
\text { contextos institucionais. }\end{array}$ \\
\hline
\end{tabular}

Fonte: dados da pesquisa (2021)

Os mecanismos institucionais, quando eficazes, levam a políticas anti má conduta de maior qualidade, mesmo que por si só não afetem a avaliação do mercado em geral, mas melhoram a avaliação corporativa, como, por exemplo, na governança e nos riscos empresariais, em países com ambientes legais e regulatórios mais fortes ( $\mathrm{Li}$ et al., 2016). Por outro lado, ambientes institucionais fracos tendem a uma maior concentração de poder e uma maior chance de expropriação dos stakeholders, como por exemplo, dos acionistas minoritários (Driffield, Mickiewicz \& Temouri, 2014). Dessa forma, a especificidade de cada organização e do país onde esteja situada, influencia na eficácia de mecanismos institucionais internos e externos, como composição do conselho, remuneração de executivos e divulgação de relatórios estratégicos, e, consequentemente, impactam no desempenho corporativo.

A criação e manutenção de normas contribui para que os interesses dos stakeholders sejam alinhados, e a elaboração dessas práticas pode considerar o isomorfismo coercitivo e mimético, para o alcance de legitimidade (Bender, 2004; Johanson \& Østergren, 2010). As características isomórficas também podem estar presentes na maneira como é realizada a divulgação de informações da empresa, a exemplo dos indicadores de desempenho sociais, ambientais e o retorno financeiro (Almeida \& Callado, 2014). Em consonância, a corrente NIS da Teoria Institucional prega que a adequação das organizações perante às normas sociais é necessária para a sobrevivência e manutenção do elevado nível de eficiência produtiva (Covaleski; Dirsmith \& Samuel, 1996).

As normas sociais, refletidas nas dimensões nacionais, são capazes de moldar e legitimar estruturas de governança (Li \& Harrison, 2008), e de reafirmar que os diferentes aspectos da lógica e da criação humana podem representar um diferencial e contribuir para engajamento dos colaboradores interessados em maximização da utilidade. Essas normas culturais nacionais podem impactar nos incentivos para que os atores das organizações maximizem suas utilidades, a partir das estruturas corporativas.

O desempenho financeiro organizacional e a evolução do ambiente institucional encontram-se atrelados à literatura (Ntim \& Soobaroyen, 2013). Em contextos caracterizados por grandes (pequenas) imperfeições e instituições de apoio fracas (fortes), negócios afiliados superam (não superam) empresas independentes em termos de desempenho financeiro. Nesse sentido, as práticas e os resultados da gestão dependem do exercício do poder elencado nas instituições.

Temas de interesse social, como RSC e sustentabilidade, vêm recebendo atenção do planejamento financeiro das organizações (Ikram, Li \& Minor, 2019; Nandy et al., 2020; Ntim \& Soobaroyen, 2013). Esses temas podem ser frutos dos acontecimentos contemporâneos que justificam uma estrutura corporativa e institucional cada vez mais inclinada com a temática de proteção e inserção de temas sociais e ambientais nas agendas das corporações, com o objetivo de alcançar maior legitimidade. Em concordância, a abordagem institucional NIE afirma que as pressões dos mercados justificam a existência de organizações de natureza capitalista (Pereira \& Lopes, 2018), reforçando que as empresas buscam legitimidade ao melhorar seu desempenho socioambiental, ao mesmo tempo que a sociedade reivindica que as empresas adotem práticas de RSC.

Características ambientais e institucionais (eficiência dos mercados, controle corporativo, transparência de informações, competição, liquidez, pressões externas e institucionais) são incorporadas nas agendas de pesquisas em finanças, na tentativa de explicar fenômenos que antes permaneciam lacunas argumentativas e sem respaldo na literatura, como exemplo, essas características foram apontadas como capazes de influenciar as possibilidades de sucesso da F\&A. Sob a ótica da Teoria Institucional, o fracasso ou sucesso dos negócios é influenciado pelo ambiente institucional em países com maior liberdade econômica e barreiras de entradas de novos concorrentes (Attah-Boakye et al., 2020).

A corrupção nas organizações possui aspectos socioeconômicos e depende dos ambientes institucionais e culturais. Em termos gerais, as estruturas corporativas necessitam se adaptar à cultura 
nacional para sobreviverem e conseguirem legitimidade. Além disso, a cultura consegue explicar o nível de corrupção presente no ambiente institucional de cada país (Boateng et al., 2020). Nesse sentido, a cultura pode ser um fator importante para explicar o comportamento dos sistemas financeiros.

Ambientes institucionais mais fortes, com leis e sistemas políticos estáveis, fornecem maiores benefícios para as organizações e stakeholders, como, por exemplo, maior captação de recursos e financiamentos de longo prazo (Awartani, 2016), devido à confiança que os credores possuem com as características desse ambiente. Além disso, estruturas com maior divulgação de risco tendem a conquistar maior reputação, isso por meio de informações verídicas, sejam informações positivas, neutras ou negativas (Derouiche, Muessig \& Weber, 2020), ratificando os processos de legitimidade. Conforme a corrente institucional $O I E$, as empresas desenvolvidas se tornam destaque pela atuação rotineira de atividades humanas desempenhadas com qualidade e confiança (Guerreiro et al., 2005).

Reorganizações estruturais são fruto de um processo constante e contínuo de maturação das organizações e do contexto socioeconômico na qual estão inseridas. Cada região produz uma dinâmica própria capaz de canalizar quais instituições serão capazes de obter sucesso financeiro em um determinado ambiente. Nesse sentido, o campo das finanças vem aportando discussões da Teoria Institucional com o objetivo de compreender fenômenos não explicados inicialmente pelo próprio campo de investigação.

\section{Considerações Finais}

Neste estudo, utilizou-se 32 artigos para investigar os avanços dos estudos nacionais e internacionais em finanças que estão utilizando a Teoria Institucional como plataforma teórica. Não foram identificados estudos anteriores que sintetizem o uso dessa teoria no campo das finanças. 0 estudo mais próximo foi de Soeiro e Wanderley (2019), que sintetizaram o conhecimento gerado pela Teoria Institucional em contabilidade, uma das bases das finanças. 0 presente estudo constitui uma das primeiras tentativas de sintetizar a Teoria em Finanças com sua aplicabilidade, essa em diferentes contextos, como em economias emergentes e desenvolvidas, países regidos pelo direito civil e direito consuetudinário, dentre outros.

As evidências da pesquisa sugerem que a Teoria Institucional trouxe importantes contribuições nas pesquisas em finanças ao explicar a estrutura e o funcionamento das organizações construídas de maneira social em função de regras, crenças e valores na qual se inserem. Esse impacto reflete nas explicações e fundamentações das principais linhas de pesquisa em finanças, como governança corporativa, fusões \& aquisições, risco, investimento e financiamento, divulgação e mensuração do desempenho, dentre outros.

Fornecendo implicações para a Teoria Institucional, esta pesquisa demonstra o quanto as características institucionais interagem de maneira complementar para o desenvolvimento dos mercados financeiros ao adotarem práticas que sejam legitimadas pelos principais stakeholders. Nas implicações para as finanças, é possível observar um passo adiante à reestruturação do campo ao incorporar pressões sociais e internacionais, como boas práticas de governança, responsabilidade social corporativa, sustentabilidade, dentro outras, no campo de pesquisa em finanças.

As descobertas da presente pesquisa também trazem implicações importantes para os formuladores de políticas, reguladores e gestores. Por exemplo, a regulação poderá ser adotada de maneira a melhorar os processos gerenciais, ou ser adotada por questões de legitimidade perante os stakeholders para garantir sua sobrevivência por mais tempo. Por outro lado, a legislação poderá não ser aceita pelas organizações e estas migrem para outros ambientes que melhor lhes convém. Dito isso, é importante que os formuladores de políticas e reguladores levem em consideração a reação ao ambiente que as organizações podem ter, pois elas também podem exercer pressões no ambiente.

De maneira geral, a presente pesquisa também possui limitações. Uma limitação encontrada diz respeito à quantidade de revistas especializadas em finanças no Brasil de alto impacto, sendo encontrada apenas duas revistas que juntas tinham quatro artigos publicados com a Teoria Institucional, outro resultado que demonstra a escassez de pesquisas a nível nacional que alia essa teoria e o campo das finanças. Outra limitação encontrada foi a dissociação de pesquisas em finanças e em contabilidade, pois por vezes compartilham o mesmo espaço, o que pode trazer implicações para os resultados da presente pesquisa. Há limitação também em relação às revistas que poderiam ser utilizadas, pois foram encontrados outros estudos em finanças publicados em revistas de alto nível, mas que não são revistas especializadas, e sim gerais, o que dificulta a generalização dos resultados.

As limitações são insuficientes para ignorar o quanto a Teoria Institucional contribuiu e o ainda pode contribuir para o campo das finanças. Além das sugestões de pesquisas supracitadas ao decorrer dos resultados, sugere-se a expansão das linhas de pesquisa, como, por exemplo, aliar a Teoria Institucional e as finanças comportamentais, bem como a necessidade de mais estudos nas linhas de 
fusões \& aquisições, implicações de gerenciamento de resultados, risco, investimento e financiamento, dentre outras.

\section{Referências}

Almeida, K.K.N., Callado, A.L.C. (2017). Indicadores de Desempenho Ambiental e Social de Empresas do Setor de Energia Elétrica Brasileiro: uma análise realizada a partir da ótica da Teoria Institucional. Revista de Gestão, Finanças e Contabilidade, 7(1), 222-239.

Attah-Boakye, R., Guney, Y., Hernandez-Perdomo, E., \& Mun, J. (2020). Why do some merger and acquisitions deals fail? A global perspective. International Journal of Finance \& Economics, 1(43), 55-76.

Awartani, B., Belkhir, M., Boubaker, S., \& Maghyereh, A. (2016). Corporate debt maturity in the MENA region: does institutional quality matter?. International Review Of Financial Analysis, 46(1), 309-325.

Barley, S. R. \& Tolbert, P. S. (1997) Institutionalization and Structuration: studying the links between action and institution, Organization Studies, 18(1), 93-117.

Bender, R., Why Do Companies Use Performance-Related Pay for Their Executive Directors? Corporate Governance, 12(4), 521-533.

Boateng, A., Wang, Y., Ntim, C., \& Glaister, K.W. (2020). National culture, corporate governance and corruption: a cross country analysis. International Journal Of Finance \& Economics, 1(23), 355-376.

Buallay, A., Hamdam, R., Barone, E., \& Hamdam, A. (2020). Increasing female participation on boards: Effects on sustainability reportinge. International Journal Of Finance \& Economics, 1(14), 145-156.

Chakrabarty, S., Bass, A. E. (2014). Corporate Governance in Microfinance Institutions: board composition and the ability to face institutional voids. Corporate Governance: An International Review, 22(5), 367-386.

Chenhall, R. H. \& Smith, D. (2011). A review of Management Accounting Research: 1980-2009. Accounting and Finance, 51(1), 173-206.

Chhatwani, M. N. (2019). Reflections on theories of market efficiency. Journal Public Affairs, 19(4), 1-5.

Chizema, A. (2008). Institutions and Voluntary Compliance: the disclosure of individual executive pay in germany. Corporate Governance: An International Review, 16(4), 359-374.

Covaleski, M. A., Dirsmith, M.W.; \& Samuel, S. (1996). Managerial accounting research: the contributions of organizational and sociological theories. Journal of Management Accounting Research, 8(1), 1-35.

Dacin, M. T., Goodstein, J. \& Scott, W. R. (2002). Institutional Theory and Institutional Change: introduction to the special research forum. The Academy Of Management Journal, 45(1), 1-43.

Derouiche, I., Muessig, A., \& Weber, V. (2020). The effect of risk disclosure on analyst following. The European Journal of Finance, 26(14), 1355-1376.

DiMaggio, P. \& Powell, W. (1983). The Iron Cage Revisited: Institutional Isomorphism and Collective Rationality in Organizational Fields. American Sociological Review, 48(2), 147.

Driffield, N., Mickiewicz, T., \& Temouri, Y. (2014). Institutions and Equity Structure of Foreign Affiliates. Corporate Governance: An International Review, 22(3), 216-229.

$\mathrm{Du}, \mathrm{M}$., Boateng, A., \& Newton, D. (2015). The impact of state ownership, formal institutions and resource seeking on acquirers' returns of Chinese M\&A. Review Of Quantitative Finance And Accounting, 47(1), 159-178.

Eng, L. L., Fang, H., Tian, X., Yu, T. R., \& Zhang, H. (2019). Financial crisis and real earnings management in family firms: a comparison between China and the United States. Journal Of International Financial Markets, Institutions And Money, 59(1), 184-201.

Goodell, J. W. (2019). Comparing normative institutionalism with intended rationality in culturalfinance research. International Review Of Financial Analysis, 62(1), 124-134.

Guerreiro, R., Frezatti, F., Lopes, A. B., \& Pereira, C. A. (2005). O entendimento da contabilidade gerencial sob a ótica da Teoria Institucional. Organizações \& Sociedade, 12(35), 91-106.

Ikram, A., Li, Z. Frank., \& Minor, D. (2019). RSC-contingent executive compensation contracts. Journal of Banking \& Finance, 27(1), 105655-105674.

Iquiapaza, R. A., Amaral, H. F., Bressan, A. A. Evolução da pesquisa em finanças: epistemologia, paradigma e críticas. Organizações \& Sociedade, 16(49), 351-370.

Jacoby, G., Liu, M., Wang, Y., Wu, Z., \& Zhang, Y. (2019). Corporate governance, external control, and environmental information transparency: evidence from emerging markets. Journal of International Financial Markets, Institutions And Money, 58(1), 269-283.

Johanson, D., ØSTERGREN, K. (2010). The Movement Toward Independent Directors on Boards: a comparative analysis of Sweden and the UK. Corporate Governance: An International Review, 18(6), 527-539. 
Judge, W. Q., Gaur, A., \& Muller-Kahle, M. I. (2010). Antecedents of Shareholder Activism in Target Firms: evidence from a multi-country study. Corporate Governance: An International Review, 18(4), 258-273.

Kwabi, F. O., Boateng, A., \& Adegbite, E. (2018). International equity portfolio investment and enforcement of insider trading laws: a cross-country analysis. Review Of Quantitative Finance And Accounting, 53(2), 327-349.

Leonel, R. \& Cunha, C. (2013). Atores, trabalho institucional e a institucionalização da estratégia de diversificação em uma cooperativa agroindustrial. BASE - Revista de Administração e Contabilidade da Unisinos, 10(1).

Li, C., Li, J., Liu, M., Wang, Y., \& Wu, Z. (2017). Anti-misconduct policies, corporate governance and capital market responses: international evidence. Journal of International Financial Markets, Institutions And Money, 48(1), 47-60.

Li, J., Harrison, J. R. (2008). National Culture and the Composition and Leadership Structure of Boards of Directors. Corporate Governance: An International Review, 16(5), 375-385.

Li, W., Wang, C., Ren, Q., \& Zhao, D. (2020). Institutional distance and cross-border M\&A performance: a dynamic perspective. Journal of International Financial Markets, Institutions And Money, 66(1), 101207-101230.

Matos, T. M. P., Santos, O. M., Rodrigues, A., Leite, R. O. (2018). Lobbying on audit regulation at IAASB. Revista Contabilidade \& Finanças, 29(77), 246-265.

Meyer, J. W. \& Rowan, B. (1977) Institutional Organizations: Formal Structure as Myth and Ceremony, American Journal of Sociology, 83(2), 340 - 363.

Moll, J., Burns, J. \& Major, M.J. (2006). Institutional Theory. Methodological Issues in Accounting Research: Theories, Methods and Issues. London: Spiramus.

Moura, A. A. F., Domingos, S. R. M., Cabral, A. C. A., \& Santos, S. M. (2014). A governança corporativa sob a ótica do isomorfismo: uma análise do setor bancário da BM\&FBOVESPA. Revista de Gestão, Finanças e Contabilidade, 4(3), 23-44.

Nandy, M., Lodh, S., Kaur, J., \& Wang, J. (2020). Impact of directors' networks on corporate social responsibility: a cross country study. International Review Of Financial Analysis, 72(1), 101601-101623.

Nguyen, T. H. H.; Ntim, C. G.; \& Malagila, J. K. (2020). Women on corporate boards and corporate financial and non-financial performance: a systematic literature review and future research agenda. International Review Of Financial Analysis, 71(1), 101554-101578.

Nguyen, T., Locke, S., \& Reddy, K. (2015). Ownership concentration and corporate performance from a dynamic perspective: does national governance quality matter?. International Review of Financial Analysis, 41(1), 148-161.

Ntim, C. G., Lindop, S., \& Thomas, D. A. (2013). Corporate governance and risk reporting in South Africa: a study of corporate risk disclosures in the pre- and post-2007/2008 global financial crisis periods. International Review Of Financial Analysis, 30(1), 363-383.

Ntim, C. G.; Soobaroyen, T. (2013). Corporate Governance and Performance in Socially Responsible Corporations: new empirical insights from a neo-institutional framework. Corporate Governance: An International Review, 21(5), 468-494.

Pereira, A. J., Lopes, H. C. (2018). The market for the "old" and the "new" institutional economics. Brazilian Journal Of Political Economy, 38(3), 450-468.

Russo, P. T., Parisi, C., Megliorini, E., \& Almeida, C. B. (2012). Evidence of institutionalizing elements in the Balanced Scorecard in the book Strategy in action: a view based on institutional theory. Revista Contabilidade \& Finanças, 23(58), 7-18.

Scapens, R. W. (2006). Understanding management accounting practices: a personal journey. The British Accounting Review, 38(1), 1-30.

Scott, R (2001). Institutions and Organizations (2a ed.). California: Sage, 280 p.

Simkowitz, M. A. (1972). Modern financial theory: Impact on analysis of stragey. Business Horizons, 15(1), 89-96.

Soeiro, T. M. \& Wanderley, C. A. (2019). A teoria institucional na pesquisa em contabilidade: uma revisão. Organizações \& Sociedade, 28(89), 291-316.

Yamahaki, C., Frynas, J. G. (2016). Institutional Determinants of Private Shareholder Engagement in Brazil and South Africa: the role of regulation. Corporate Governance: An International Review, 24(5), 509-527.

Zattoni, A., Cuomo, F. (2008). Why Adopt Codes of Good Governance? A Comparison of Institutional and Efficiency Perspectives. Corporate Governance: An International Review, 16(1), 1-15. 
Zattoni, A., Pedersen, T., \& Kumar, V. (2009). The Performance of Group-affiliated Firms during Institutional Transition: a longitudinal study of indian firms. Corporate Governance: An International Review, 17(4), 510-523.

Zucker, L. G. (1977) The Role of Institutionalization in Cultural Persistence. American Sociological Review, 42(5), 726-743. 